\title{
Lengthening of time estimates in four different temporal patterns of visual light stimulation
}

\author{
DOUGLAS A. ROSS, ${ }^{1}$ Lehigh University, \\ Bethlehem, Pa. 18015
}

Lengthening in time estimates has been described by several authors. Thirty-six $S_{s}$ produced estimates of a 10-sec interval over 29 sequential trials under one of four environmental conditions, steady illumination (SI), darkness (D), intermittent photic stimulation with a dark background (IPSD), and intermittent photic stimulation with ambient light (IPSA). Differences from zero trend and other trend differences were produced for all pairs except SI and IPSA. Results were interpreted as evidence favoring Treisman's model of the intemal clock.

Treisman (1963) defines the lengthening effect in sequential time estimate trials as "the increase in the mean judgments during the course of a session." In a series of experiments he found lengthening to be the usual case when using the method of production (MP) and the method of reproduction (MR) (Clausen, 1950). He also showed that the phenomenon was not related to decrease in motor reaction time with fatigue. A model of the internal time-keeping mechanism was proposed in which lengthening was attributed to changes in the activity of a specific arousal center, which increased the rate of activity in some hypothetical neural pathways in the CNS. No systematic course was observed, with lengthening sometimes occurring predominantly in early trials, and sometimes in later trials. In all cases, in tervals to be produced or reproduced were filled with either steady auditory or visual stimuli.

Both Eson \& Kaffka (1952) and Falk \& Bindra (1954) reported tendencies for length of time productions to increase over sequential trials. Several authors (Rosenzweig \& Koht, 1933; Langer, Wapner, \& Werner, 1961; Hawkes, Joy, \& Evans, 1961; Thor, 1962) have obtained lengthened time estimates in experimental conditions which assumedly lead to increases in arousal. These studies confirm the predictions from Treisman's model.

The studies of time perception mentioned above have usually been carried out only with steady stimulus conditions present

Fig. 1. Time estimate functions in SI, D, IPSA, and IPSD conditions. during estimation. Other temporal patterns of stimulation have been overlooked. The experiment described here was constructed to examine various temporal patterns of visual light stimulation as they influence time productions. An attempt was made to determine whether these different conditions would lead to different trends in time estimation in the course of an experimental session. If they should lead to such pattern differences, then, according to Treisman's model, they should influence the specific arousal center differentially. Lengthened time estimates were expected in all conditions, and differences in amount of lengthening in a session were explored.

\section{METHOD}

Thirty-six male Ss obtained from general psychology classes at Lehigh University were randomly assigned to one of four conditions: steady illumination (SI); dark (D), intermittent photic stimulation with a dark background (IPSD); and in termittent photic stimulation with ambient light (IPSA). Each was brought to the experimental chamber and asked to recline in a modified barber chair. Eyecups, constructed from halves of ping-pong balls, were worn in all conditions in order to provide a homogeneous visual field. Ss were told that they would be producing a 10 -sec interval over a number of trials. If the $S$ was to receive either Condition IPSD or IPSA, he was further acquainted with the condition. Each $S$ was told to produce the in terval by

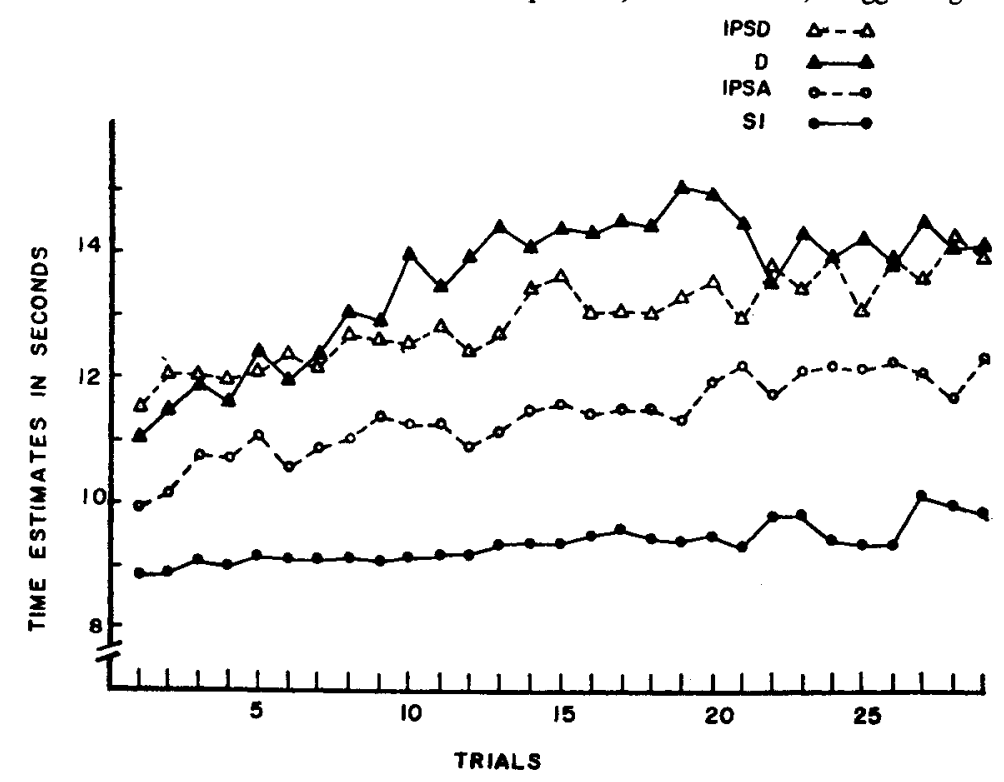
tially lacking measurable illumination during dark conditions. Ambient light was at $2.61 \mathrm{ft}-\mathrm{L}$ at S's eyecups for SI and IPSA conditions. A Grass Model PS-2 photostimulator, with intensity set at 8 , was used to produce IPS. The lamp was suspended from the ceiling of the experimental chamber in such a way that its face was parallel to the plane of S's body, at a distance of $20 \mathrm{in}$. from his face.

A Lindquist (1953) Type 1 mixed design was used with the inclusion of tests of trend differences. In light of the results of the Norton study (1952), no tests of homogeneity of variance were carried out.

\section{RESULTS}

The significant A by B interaction ( $F=2.52, \mathrm{df}=84 / 896, \mathrm{p}<.01)$ indicated that further trend analyses were necessary. Pairwise $F$ tests of parallel slope indicated that only differences in trends of SI and IPSA, and SI and IPSD were not significant $(\mathrm{df}=28 / 896, \mathrm{p}<.01)$. All other pairs differed. Further pairwise $F$ tests of overall condition means indicated that time productions during SI were significantly shorter than in $D(F=9.46, d f=1 / 32$, $\mathrm{p}<.01)$ and IPSD $(F=7.01$, df $=1 / 32$, $\mathrm{p}<.01)$. These tests indicate that all pairwise trends differ except IPSA and SI. Individual $\mathrm{T}$ by $\mathrm{S}$ designs for each treatment indicate all slopes to differ significantly (Fs = 7.70, 4.13, 3.27, 4.10; df = 28/224; $p<.01$ ) from zero, suggesting that a

pulsing a button $10 \mathrm{sec}$ after he heard a momentary auditory tone.

A standard electric timer was activated along with the tone, and deactivated when the $S$ pressed his switch terminating the interval. Ss produced 29 consecutive $10-\mathrm{sec}$ intervals at a rate of approximately $2 / \mathrm{min}$.

The experimental chamber was essen-

\footnotetext{
(n)
}


lengthening effect is present in all four conditions (see Fig. 1).

\section{DISCUSSION}

The presence of a significant lengthening trend in all conditions supports Treisman's model of the internal clock. An ex tension of the model might predict that in environments which lead to an increase in the activities of the specific arousal center time estimates should be shorter. This would be manifested in this study if darkness was the least arousing of the conditions in this study, with IPSD, IPSA, and SI leading to greater and greater activity in the specific arousal system. Except for the lack of any significant trend differences between $\mathrm{SI}$ and IPSA, the above proposal was supported here. While other authors (Falk \& Bindra, 1954; Eson \& Kaffka, 1952) have reported linear lengthening, none have sought to determine the extent of the phemonenon. Treisman found lengthening highly irregular, sometimes greater in the beginning, sometimes greater later on in a series of trials. In the present study, lengthening seems to advance more rapidly in the first 15 or 16 trials in D, IPSD, and IPSA conditions (see Fig. 1). Indeed, those values seem to level off at that point and remain fairly stable. In SI conditions, greater lengthening effects seem to occur between the 15 th and 29 th trials. It should be noted that overall means in SI are less than in any other condition.

The leveling-off phenomenon could be attributed to some adaptation on the part of the $S$ to the "new" experimental environment. The Ss were taken immediately into the experimental environment upon showing up for the experiment. It took about 8 or 9 min to complete 15 trials, and it might be reasoned that it took them that long to settle down. Falk \& Bindra (1954), Rosenzweig \& Koht (1933), Hawkes, Joy, \& Evans(1961), and Thor (1962) have all indicated that time estimates are shorter under conditions leading to greater arousal.
The present study has shown that time estimates are affected differentially by differing temporal patterns of visual light stimulation, and that lengthening in time estimates fits a model of an arousal system influencing time productions.

Previous studies indicated that time estimates lengthen over a series of trials. Treisman (1963) postulated a model of an internal clock in which lengthening was related to decreased activity in a specific arousal system in the CNS. The present study identified differential lengthening trends in varying temporal patterns of light stimulation, and accounted for those differences using Treisman's model.

\section{REFERENCES}

CLAUSEN, J. An evaluation of experimental methods of time judgment. Journal of Experimental Psychology, 1950, 40, 756-761.

ESON, M., \& KAFFKA, J. Diagnostic implications of a study in time perception. Journal of General Psychology, 1952, 46, 169-183.

FALK, J., \& BINDRA, D. Judgment of time as a function of serial position and stress. Journal of Experimental Psychology, 1954, 47, 279-282.

HAWKES, G., JOY, R., \& EVANS, W. Autonomic effects on estimates of time: Evidence for a physiological correlate of temporal experience. U.S. Army Medical Research Laboratory Report No. 506, 1961.

LANGER, J., WAPNER, S., \& WERNER, $H$. The effect of danger upon the experience of time. American Journal of Psychology, 1961, 74, 94-97.

LINDQUIST, E. Design and analysis of experiments in psychology and education. Boston: Houghton Mifflin Co., 1953.

ROSENZWEIG, S., \& KOHT, A. The experience of duration affected by need tension. Journal of Experimental Psychology, 1933, 16, 745-775. THOR, D. Diurnal variability in time perception Unpublished doctoral dissertation, Florid State University, 1962.

TREISMAN, M. Temporal discrimination and the indifference interval: Implications for a model of the "internal clock." Psychological Monographs, 1963, 77, No. 13 (Whole No. 576).

NOTE

1. Now at Monmouth College, Monmouth, Ill. 61462. two components of the modeling stimulus, one group of 5-year-olds observed a model manipulate stimulus objects and then was given an opportunity to play with those objects; a second group played with the same objects after observing the model manipulate different objects. A significant modeling effect and a significant enhancement effect were obtained. Although the magnitude of the enhancement effect was small, the results indicate that a precise assessment of the modeling effect requires an enhancement control condition.

The term, imitation, may be applied when an $\mathrm{O}$ emits responses previously performed by a model and which occur as a function of observing those responses. Observation of the model's performance includes both the observation of specific responses and observation of a person behaving in an environmental setting. Observation of a behaving person could increase the response rate of $S$ and the number of ways in which $S$ manipulates the available stimulus objects. Such performance would increase the likelihood of $S$ performing the imitative responses. If an increase in imitative responses occurred, it could be called an enhancement effect. Bandura, Ross, \& Ross (1963) have indicated the need to determine the enhancement effect; without a control for enhancement it is not possible to attribute S's matching responses to observation of the modeled responses. Studies which have attempted to control for the enhancement effect have used a control procedure in which $S$ could exhibit both the responses exhibited by the behaving person and those responses defined as imitative responses (Bandura, Ross, \& Ross, 1961, 1963; Walters \& Willows, 1968). Under such a condition, the enhancement effect could be concealed to the extent that the Ss in the enhancement condition performed the responses exhibited by the behaving person.

The aim of this study was to determine whether a modeling effect, i.e., imitation, could be obtained after partialling out any possible enhancement effect. In a model condition, Ss had the opportunity to play with the same set of stimulus materials they observed the model manipulate. Ss in the enhancement condition played with the same set of stimulus materials, but they previously observed the model manipulate a different set of stimulus materials. In another condition, the no-model condition, Ss were not exposed to a model but to a cartoon film. The modeling effect can be assessed by comparing the difference in the number of matching responses in the model and enhancement conditions. The entancement effect can be assessed by comparing the difference in the number of
DAVID A. PARTON and RICHARD A. DUBANOSKI, Institute of Child Behavior and Development, University of Iowa, Iowa City, Iowa 52240

The observation of a model performing

responses may facilitate the reproduction of those responses by $S s$ as a function of observing those specific responses (a modeling effect) or as a function of simply observing a performing model (an enhancement effect). To investigate these 